Journal of Mathematics and Informatics

Vol. 14, 2018, 45-52

ISSN: 2349-0632 (P), 2349-0640 (online)

Published 6 September 2018

www.researchmathsci.org

DOI: http://dx.doi.org/10.22457/jmi.v14a6

Journal of

Mathematics and

Informatics

\title{
The Researches on the Impact of Community Q\&A Information Quality on Consumers' Purchase Intention
}

\author{
Xiao-ping Liu and Wen-xiang Deng \\ School of Economics and Management, Chongqing University of Posts and \\ Telecommunications, Chongqing - 400065, Chongqing, China. E-mail: \\ liuxiaoping@cqupt.edu.cn
}

Received 8 August 2018; accepted 4 September 2018

\begin{abstract}
Based on the analysis of community question and answer information quality (this study uses the Taobao shopping platform as the research object), the customer perceived value is taken as the intermediary variable, and the product type is introduced as the adjustment variable between the community question answering information quality and the perceived value. The conceptual model of the influence of community question and answer information quality on consumers' purchase intention was used to collect data using questionnaires and validate the model through empirical analysis. The study found that Q\&A information has a significant positive effect on consumers' purchase intention. Perceived value plays a complete intermediary role between Q\&A information quality and purchase intention. There is a moderating effect of the product type on Q\&A information quality and purchase intention. When the product is a search product, Q\&A information quality has a significant positive effect on the purchase intention; when the product is an experiential product, the Q\&A information quality has no significant effect on the purchase intention.
\end{abstract}

Keywords: community Q\&A information quality; customer perceived value; product types; purchase intention

\section{AMS Mathematics Subject Classification (2010): J0254}

\section{Introduction}

As an important part of the national economy, the Internet economy is mainly benefited from the rise of e-commerce and its huge scale. Therefore, the e-commerce industry has always been the focus of social attention. The emergence of eBay, Taobao, Amazon and other online shopping platforms has led to a continuous increase in the number of Internet users in recent years. According to the 2017 annual statistical report released by the China Internet Network Information Center, as of June 2017, the number of online shopping users has reached 514 million, accounting for $68.4 \%$ of the groups. On these online shopping platforms, many consumers actively or passively share their sense of shopping experience and evaluation of the use of products, in order to make reference for other consumers to buy. However, the contents and forms of sharing vary from person to person, and a large number of favorable comments, bad reviews, reviews, picture comments, or text-only comments have greatly enriched the information of related 


\section{Xiao-ping Liu and Wen-xiang Deng}

products. In the face of numerous reviews, consumers often need to spend a lot of time and energy screening effective information, which to a certain extent, reduce the patience of consumers for the product, affecting its purchase decision. The existing problems have promoted the emergence of the community question answering system, which reflects the important value of the community question and answer information.

Consumers are the ultimate recipients of the community question and answer system, so the quality of question and answer information has an absolute leading role in consumer buying behavior. Different core products have different core features, and consumers' perceptions of the quality of question and answer information vary. According to product characteristics, consumers' perception of the quality of question and answer information is improved, consumers' psychological risks are reduced, and product purchase or community identification will be enhanced. This article starts from the community question and answer, uses the customer perceived value as an intermediary, establishes the model of community questioning information quality impact on consumers' purchase intention, and discusses the adjustment effect of product type in community question answering information quality and customer perceived value. It plays an important role in improving the level of the Internet economy and promoting the development of e-commerce.

\section{Literature review}

\subsection{Community Q\&A information quality}

Community Q\&A (CQA) has become a new paradigm for seeking and sharing information. It means that its users can ask questions or answer questions raised by others through the Internet platform [1], such as Google, Zhihu, and other social platforms. The emergence of community Q\&A has enriched consumers' access to online information [2]. Compared to traditional online information, community Q\&A information enables consumers to obtain more effective information and reduce the time and effort spent filtering information [3]. Diane et al. (1997) proposed that information quality can be divided into four parts: internal information quality, availability information quality, context information quality, and expression information quality [4]. Liu \& Zhang (2010) and others studied the impact of online feedback on the degree of consumer information adoption. The higher the consumer's perceived usefulness to online feedback, the higher the likelihood of using information [5]. Since entering the Web 2.0 era, online shopping consumers have increasingly relied on question and answer information [6]. Since the advent of the online shopping platform "Ask everyone", its evaluation system has deeply influenced the various stages of consumer decision-making [7]. Few studies have involved the quality of question and answer information about online shopping platforms. According to the classification of information quality by Diane (1997), this paper divides the quality of shopping platform Q\&A information into three main levels: content information quality, context information quality and expression quality, and studies the impact of question and answer information quality on consumers' purchase intention.

\subsection{Customer perceived value}

Since the appearance of customer perceived value (CPV) since 1980, the definition given by research scholars has been very similar. BAKER et al. (1997) argue that customer perceived value refers to the comparison between perceived value and perceived costs 
The Research on the Impact of Community Q\&A Information Quality on Consumers' Purchase Intention

generated by consumers in the process of selecting goods [8]. Zeithaml (1988) defines customer perceived value as a comparison between cost and benefit, and is an overall evaluation of the product [9]. The customer perceived value in this article refers to the subjective evaluation of the product formed after the consumer weighs the pay and benefits, and then affects the consumer's subsequent decision-making behavior. With the deepening of research on customer perceived value in the academic community, customer perceived value has been refined, most of them agree with the classification of Sweeney (2001), that is, customer perceived value is divided into emotional value, social value, functional value, and efficacy value [10].

\subsection{Product types}

Nelson (1970) classified products into experiential products and search products [11] based on the ability of consumers to obtain product information. Experiential products refer to the fact that consumers do not know their detailed information before buying a product because of their lack of direct experience. There are certain difficulties in such information [12], such as clothing, skin care products, etc.; search products means that consumers have known all product attribute information [13], such as books, electronic products, etc. before purchasing the product. Due to the essential difference between the experiential product and the search product, scholars in the e-commerce field consider the adjustment role of the product type when studying consumer behavior [14].

\section{Research hypotheses}

\subsection{The relationship between community $Q \& A$ information quality and consumers' purchase intention}

Community Q\&A is one of the ways consumers feedback online. Through feedback information, consumers can obtain content related to purchase decision [2]. Juliet (2017) and other experimental studies have shown that online information quality has a positive effect on consumers' purchase intention [15]. The review information of the virtual community platform has a significant impact on consumers. Therefore, this study proposes the following assumptions:

H1: The quality of community question and answer information has a positive effect on consumers' purchase intention.

\subsection{The relationship between community Q\&A information quality, customer perceived value and consumers' purchase intention}

Wang et al. (2017) showed that the perceived usefulness of consumer information on online food safety has a positive impact on continuous search behavior [14]. From the perspective of consumers, the quality of Internet word-of-mouth information has a positive impact on its perceived value [16]. When consumers perceive that the higher the consistency between word-of-mouth information and product image, the higher the perceived value [17], the higher the adoption rate of information [5], and the greater the likelihood of consumers purchasing [17]. Hsin et al. (2009) pointed out that the higher the perceived value of consumers, the higher the user loyalty [18]. Consumers with higher perceived value have a stronger desire to purchase [19]. Therefore, this study proposes the following assumptions: 
Xiao-ping Liu and Wen-xiang Deng

H2: customers perceived value plays an intermediary role between community Q\&A information quality and consumers' purchase intention.

\subsection{The relationship between community $Q \& A$ information quality, product types and purchase intention}

Consumer demand for information is different for different product types [14]. Lee et al. (2014) empirically demonstrated that when the product is an experiential product, the impact of the quality of the review information on the consumer is greater than the effect of the product being a search product [20]. And because consumers cannot fully infer the authenticity of product advertisements, consumers have more trust in search products that are more familiar than those without direct experience [12], and their purchase intentions will be higher. Therefore, this study proposes the following assumptions:

H3: product types regulates community Q\&A information quality and customers perceived value.

H3a: community Q\&A information quality has a positive effect on purchase intention when it is an experiential product.

H3b: community Q\&A information quality doesn' t have a significant impact on purchase intention when it is a search product.

The conceptual model of this research is shown in Figure 1.

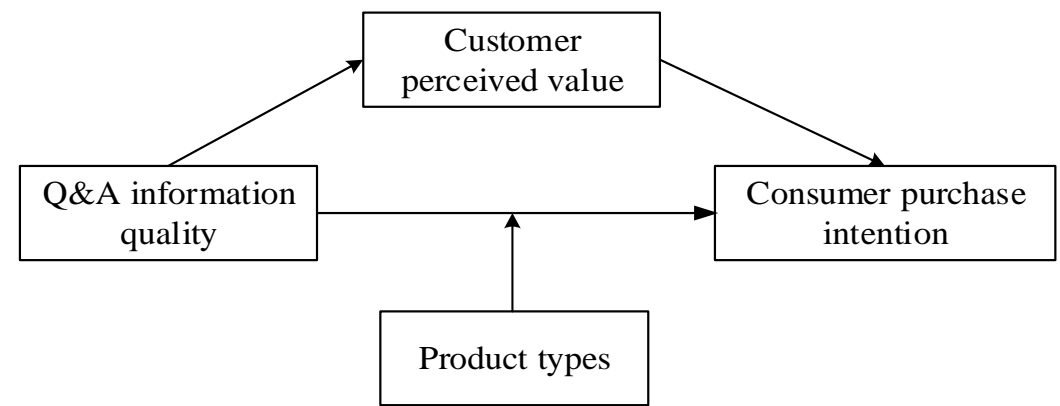

Figure 1: Research concept model

\section{Research design and data analysis}

\subsection{Product selection}

This study focuses on the regulatory effect of product types. Reference to previous research, this study classifies products into search and experiential products. In order to ensure the rigor of research, small-scale interviews are conducted before formal data collection. Determine USB Disk as a search product, Facial Cleanser as an experience product.

\subsection{Questionnaire design}

This paper collects data through the scenario questionnaire. The research model contains four variables, among which the scale questions of Q\&A information quality, customer perceived value, and purchase intention refer to domestic and international related research scales. The shopping platform Q\&A information quality measurement content and items were adapted from the literature [4]. Customer perception value variable reference [11]. Purchase willingness variable reference [21]. The questionnaires all use 
The Research on the Impact of Community Q\&A Information Quality on Consumers' Purchase Intention

the 5-level Likert scale.

\subsection{Data collection}

Questionnaires are distributed online and offline, and online through questionnaire star formation links are randomly distributed to people with online shopping experience; offline distribution is distributed to college students through paper questionnaires. A total of 160 valid questionnaires were collected finally.

\subsection{Data analysis}

Using Cronbach's $\alpha$ coefficient to test the internal consistency of the questionnaire, the overall reliability reached 0.788 . The overall reliability of the questionnaire was good. Based on the reliability of the questionnaire, the confirmatory factor analysis shows that the overall KMO value of the questionnaire reaches 0.802 , indicating the questionnaire has good validity.

The hypothesis H1 was tested by analysis of variance (ANOVA). From the results, the quality of community question and answer information has a significant positive impact on consumers' purchase intention $(\mathrm{F}=4.636, \mathrm{P}<0.05)$. Assume $\mathrm{H} 1$ is verified.

Three-step intermediate regression was used to test the hypothesis H2. First, the regression of perceived value on the quality of question and answer information was significant $(\beta=0.184, p<0.05)$. Second, the regression of the perceived value to purchase intention was significant $(\beta=0.721, \mathrm{p}<0.05)$. Third, the consumer's purchase intention reflects the return of perceived value, Q\&A information quality and their interaction items. The coefficient of interaction items is significant $(\beta=0.760, \mathrm{p}<0.05)$. The results show that the perceived value lies in the influence of the quality of question and answer information on consumers' purchase intention. Assume that $\mathrm{H} 2$ is verified.

The hypothesis $\mathrm{H} 3$ was tested by regression analysis. According to the regression analysis, the product category has a significant impact on the purchase intention $(\mathrm{t}=2.098$, $\mathrm{p}<0.05$ ), and the interaction between the quality of the question and answer information and the product type has a significant impact on the purchase intention $(\mathrm{t}=-2.404, \mathrm{p}<0.05)$. On this basis, this paper uses two-way analysis of variance to further verify the results shown in Figure 2: When the product is an experience product, the quality of question and answer information has a significant positive impact on purchase intention $(\mathrm{F}=16.423$, $\mathrm{p}<0.05$ ); When the product was a search product, the quality of question and answer information had no significant effect on consumers' purchase intention $(\mathrm{F}=0.383, \mathrm{p}>0.05)$. Assume that $\mathrm{H} 3 \mathrm{a}$ and $\mathrm{H} 3 \mathrm{~b}$ are verified. 
Xiao-ping Liu and Wen-xiang Deng

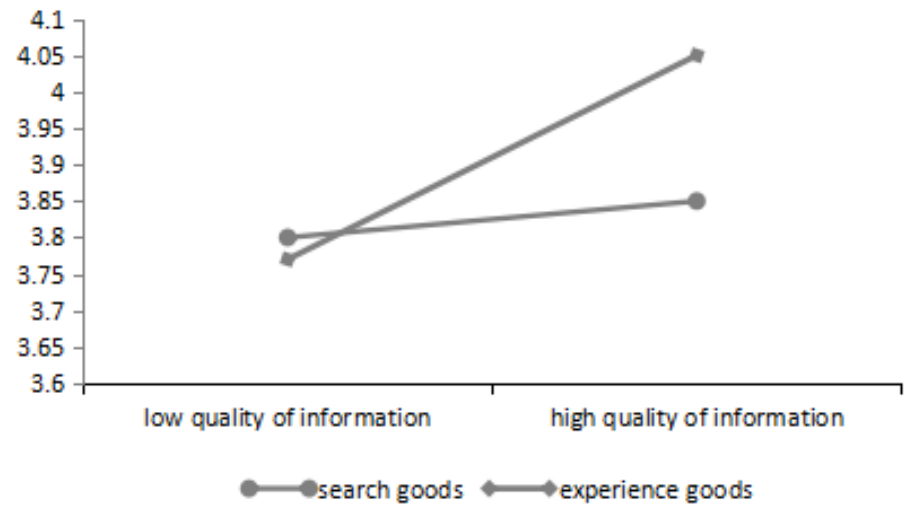

Figure 2: Regulation of product types

\section{Conclusion and inspiration}

\subsection{Conclusion}

This study constructs a conceptual model that includes community Q\&A information quality, perceived value, product types and consumer purchase intention. Based on the research results, the following conclusions are drawn: First, community Q\&A information quality has a significant positive effect on consumers' purchase intention. The impact indicated that the Q\&A information quality can be like the role of traditional online reviews, to increase consumers' purchase intention. Second, perceived value plays an intermediary role between Q\&A information quality and consumers' purchase intention. That is, Q\&A information quality has an indirect effect on the purchase intention through perceived value. Third, the product types play a regulatory role between the quality of the question and answer information and the willingness to purchase. When the product is experience products, community Q\&A information quality has a significant positive impact on the consumer's purchase intention; when the product is a search product, the influence of community Q\&A information quality to consumer purchase intention is not significant.

\subsection{The theoretical and practical significance}

The conclusions of study have great significance to e-commerce companies. First of all, companies should pay attention to the management of product's Q\&A information quality. Additionally, although paying attention to the online reviews of products, consumers are more concerned about the "inquiry people" of the products, so companies must strengthen management in order to increase their purchase intention. Second, e-commerce companies should focus on stimulating the consumers perceived value. Finally, we should pay attention to the classification and management of products. Consumers' evaluations of community Q\&A information quality for different products are not exactly the same: for the experience products, consumers mostly increase their understanding of the product by focusing on the $\mathrm{Q} \& \mathrm{~A}$ information quality and increase the purchase confidence; on the contrary, for the search products, due to consumers already have enough knowledge of target products., so the marketer should focus on the management of community Q\&A information quality for the experience products, such as 
The Research on the Impact of Community Q\&A Information Quality on Consumers' Purchase Intention

increasing the types of $\mathrm{Q} \& \mathrm{~A}$ information, make the answers more complete in $\mathrm{Q} \& \mathrm{~A}$ information and so on.

Acknowledgements. This work is supported by Chongqing Municipal Education Commission Humanities and Social Sciences Research Project (No. 18SKGH041) and Chongqing Social Science Planning Project (No. 2018YBGL065).

\section{REFERENCES}

1. Y.Yao, H.Tong, T.Xie, et al., Detecting high-quality posts in community question answering sites, Information Sciences, 302(C) (2015) 70-82.

2. R.M.Schindler and B.Bickart, Published word of mouth: referable, consumer-generated information on the internet, Online Consumer Psychology: Understanding and Influencing Customer Behavior in the Virtual World, Lawrence Erlbaum Associates. Ch.2. 2005.

3. Y.Jian and L.Yu, Answer quality evaluation model for community question answering based on hybrid method, Application Research of Computers, 34(6) (2017) 1708-1712.

4. D.M.Strong, Y.W.Lee and R.Y.Wang, Data quality in context, Communications of the Acm, 40(5) (1997) 103-110.

5. R.R.Liu and W.Zhang, Informational influence of online customer feedback: An empirical study, Journal of Database Marketing \& Customer Strategy Management, 17(2) (2010) 120-131.

6. D.H.Park, J.Lee and I.Han, The effect of on-line consumer reviews on consumer purchasing intention: the moderating role of involvement, International Journal of Electronic Commerce, 11(4) (2007) 125-148.

7. Y.Zhang, L.Z.Wei and Y.Zhao, How the information quality affects the online review usefulness? An empirical analysis based on taobao review data, Chinese Journal of Management, 14(1) (2017) 77-85.

8. J.Baker, A Parasuraman, D.Grewal, et al., The influence of multiple store environment cues on perceived merchandise value and patronage intentions, Journal of marketing, 66(2) (2002) 120-141.

9. V.A.Zeithaml, Consumer perceptions of price, quality, and value: A means-end model and synthesis of evidence, Journal of Marketing, 52(3) (1988) 2-22.

10. J.C.Sweeney and G.N.Soutar, Consumer perceived value: The development of a multiple item scale, Journal of Retailing, 77(2) (2001) 203-220.

11. P.Nelson, Information and Consumer Behavior, Journal of Political Economy, 78(2) (1970) 311-329.

12. Y.Zhang, Z.Li and B.School, Analysis of the factors that influence online reviews helpfulness: based on the regulating effect of product type, Management Review, 28(10) (2016) 123-132.

13. L.R.Klein, Evaluating the potential of interactive media through a new lens: search versus experience goods, Journal of Business Research, 41(3) (1998) 195-203.

14. X.Wang, W.Mao and J.Li, A study on the relationship between information quality, perceived usefulness and continuance search: based on the survey of online food safety information, Journal of Intelligence, 36(2) (2017) 159-164. 


\section{Xiao-ping Liu and Wen-xiang Deng}

15. L.Zhu, D.Yuan, J.Zhang, et al., The impact of online user reviews quality and commentators rank on consumer purchasing intention - the moderating role of product involvement, Management Review, 29(02) (2017) 87-96.

16. W.Y.Huang and C.F.Lao, Influence of Internet word of mouth quality on customer perceived value and purchase intention, Consumer Economics, (5) (2013) 48-53.

17. C.X.Tie, Empirical research on the eWOM Impact-A mediating role of trust and consumer perceived value, Information Science, (8) (2015) 72-78.

18. H.H.Chang, Y.H.Wang and W.Y.Yang, The impact of e-service quality, customer satisfaction and loyalty on e-marketing: Moderating effect of perceived value, Total Quality Management \& Business Excellence, 20(4) (2009) 423-443.

19. L.X.Guo, N.J.Chen and X.S.Zhang, The influence mechanism of virtual brand community 's perceived value on purchase intention of new product -based on the double mediation of group identity and brand identity, China Business \& Market, 31(2) (2017) 93-100.

20. E.J.Lee and S.Y.Shin, When do consumers buy online product reviews? Effects of review quality, product type, and reviewer's photo, Computers in Human Behavior, 31(1) (2014) 356-366.

21. C.Wan, A study of consumers' perception of online consumer reviews on different review platforms-a moderating effect of product type, Journal of Modern Information, 34(12) (2014) 154-158. 